\title{
Innovative Test Operations to Support Orion and Future Human Rated Missions
}

\author{
William J. Koenig ${ }^{1}$ and Rafael Garcia, ${ }^{2}$ \\ NASA Kennedy Space Center, Florida, 32899 \\ Richard F. Harris ${ }^{3}$ \\ ASRC Federal, Kennedy Space Center, Florida, 32899 \\ and \\ Michael J. See \\ NASA Johnson Space Center, Houston, Texas, 77058 \\ and \\ Benjamin S. Vanlear ${ }^{5}$ \\ NASA Glenn Research Center, Cleveland, Ohio, 44135 \\ and \\ Jill M. Dobson ${ }^{6}$ \\ Lockheed Martin, Kennedy Space Center, Florida, 32899 \\ and \\ Scott Norris ${ }^{7}$ \\ Lockheed Martin, Denver, Colorado, 80127
}

This paper describes how the Orion program is implementing new and innovative test approaches and strategies in an evolving development environment. The Orion program successfully completed the EFT-1 flight test in $\mathbf{2 0 1 4}$ and is currently assembling, integrating, and testing the EM-1 spacecraft to meet the flight test objectives of an unmanned orbital mission to the moon and return to earth in 2019. The EM-2 spacecraft will be the first crewed mission and is planned in 2021. The early flight test spacecraft are evolving in design maturity and complexity requiring significant changes in the ground test operations for each mission. The resulting testing approach for EM-2 is planned to validate innovative Orion production acceptance testing methods to support human exploration missions in the future. This approach will also benefit human exploration vehicles in the future in achieving affordable and low risk goals. The Orion flight test vehicle, EFT-1, was built and tested using the Neil Armstrong Operations and Checkout (O\&C) facility at the Kennedy Space Center (KSC). Orion manufacturing and testing was located at KSC to provide a seamless transition directly to the launch site avoiding transportation and checkout of the spacecraft from other locations. Innovative test operations approaches were established early on in the O\&C facility activation to integrate with the production operations providing a robust and flexible factory to meet Orion's evolving requirements. As a development flight test article, EFT-1 experienced limited acceptance testing for structural static and dynamic testing and subsystem functional test and checkout. The success of the EFT-1 mission not only validated the engineering design, both hardware and software, but also demonstrated that

\footnotetext{
${ }^{1}$ Project lead, NASA Orion Production Operation, KSC/O\&C ORION.

${ }^{2}$ Test \& Verification Lead, NASA Orion Program, KSC/O\&C ORION.

${ }^{3}$ Consultant, NASA Orion Production Operation, KSC/O\&C ORION, AIAA Member 763115.

${ }^{4}$ System Test Lead, NASA Orion Production Operation, JSC/ ZV.

${ }^{5}$ ESM Lead, NASA Orion Production Operation, GRC/86-1.

${ }^{6}$ IR\&D Lead, LM Orion production Operation, KSC/LMC-23.

${ }^{7}$ Program Development, Orion Program, 350 Glenn L. Martin Blvd, Denver,CO/B3004.
} 
the manufacturing and test operations established at the $O \& C$ were in place to support the Orion production needs in the future. The second flight test vehicle processed in the O\&C is the EM-1, which will have additional flight systems installed to fly to the moon and return. EM-1 is designed as a human rated vehicle, but will be an un-crewed mission to continue to retire risk in support of the EM-2 manned flight. The EM-1 test operations will expand to include test methods leading to an acceptable flight test vehicle, but also will support selected qualification milestones. Since the $O \& C$ facility does not currently have a system level test capability, the EM-1 spacecraft will be tested at the NASA Plum Brook Station (PBS) in Ohio using test capabilities for thermal vacuum and acoustic testing. This will require EM-1 to be transported to PBS by aircraft, tested, and returned to the $\mathrm{O \& C}$ for final checkout and integration. The program has developed a comprehensive Master Verification Plan (MVP) that defines a qualification strategy utilizing existing test facilities, innovative test methods, and multiple test articles to meet program verification objectives. This innovative system test strategy utilizes the test capabilities at PBS and the O\&C to qualify and accept the EM design using multiple flight and test articles. This approach qualifies the design and validates the acceptance test approach at the $O \& C$ avoiding the transportation of spacecraft, supporting test labor, and test tooling to PBS risk to Orion during the production phase of the program. The qualification test strategy is based on utilizing the system qualification results of the EM-1 vehicle, performing selected module level acceptance testing for the EM-2 Crew Module (CM) and Service Module (SM) separately, and validating acceptance test methods using portable test facilities for acoustic and thermal testing based on system qualification results. This approach satisfies the verification and validation objectives of "test what you fly and fly what you test" approach meeting the $\mathbf{1 0 0 \%}$ mission success goals of the Orion program. The Orion acceptance test approach for EM-2 in the O\&C utilizes the existing altitude chamber and portable test equipment to meet the environmental test requirements for a human rated vehicle. The O\&C facility has been designed with a flexible factory layout to enable the factory to be reconfigurable to meet a variety of production and test operations configurations. This approach was first used on EFT-1 and will continue into production. Acoustic testing will be accomplished using a validated approach called Direct Field Acoustic Test (DFAT). This approach uses portable acoustic "speakers" located in an open cell positioned around the spacecraft. Correlation tests were performed with the DFAT test equipment and reverberant acoustic chambers to demonstrate applicability for acceptance testing on spacecraft. Reverberant acoustic chambers can achieve higher sound pressure levels which are necessary for the qualification tests, but DFAT levels are adequate for acceptance. At the conclusion of the acoustic test the DFAT test equipment is removed and stored offline. Thermal Vacuum (TVAC) testing simulates the on-orbit environments and the Orion spacecraft design will be qualified at PBS using the TVAC chamber. A key innovation of the Orion test strategy for acceptance is performing the vacuum and temperature environmental testing separately at the O\&C. Thermal environmental testing will be accomplished using a reconfigurable thermal cell which can be erected for the test and dismantled and stored offline. Supporting fluids equipment for the thermal cell is permanently located in the basement below the test position enabling the test floor location to be available for other operations. EM-1 acceptance testing results will be correlated to the qualification results from PBS chambers to validate the $O \& C$ acceptance test processes. This innovative acceptance test approach for the Orion spacecraft provides a validated test method for production that reduces transportation risk. Additionally, this approach avoids the duplication of test chambers in the O\&C. As the Orion development program has evolved the vehicle designs and mission capabilities, the acceptance testing approaches have also matured establishing a seamless and low risk production and test capability at KSC to support future NASA Deep Space Gateway (DSG) exploration missions.

\section{Nomenclature}

$\begin{array}{ll}A A-2 & =\text { Ascent Abort }-2 \\ C A D & =\text { Computer Aided Design } \\ C C A F S & =\text { Cape Canaveral Air Force Station } \\ C M A & =\text { Crew Module Adapter } \\ D F A T & =\text { Direct Field Acoustics Test } \\ D S G & =\text { Deep Space Gateway } \\ E F T-1 & =\text { Exploration Flight Test }-1 \\ E M-1 & =\text { Exploration Mission }-1\end{array}$




$\begin{array}{ll}E M-2 & =\text { Exploration Mission -2 } \\ E S A & =\text { European Space Agency } \\ E S D & =\text { Exploration Systems Development } \\ E S M & =\text { European Service Module } \\ E T A & =\text { Environmental Test Article } \\ I C P S & =\text { Interim Cryogenic Propulsion Stage } \\ I O C & =\text { Initial Operational Capability } \\ L A S & =\text { Launch Abort System } \\ L E O & =\text { Low Earth Orbit } \\ L M & =\text { Lockheed Martin Space Systems Company } \\ M P C V & =\text { Multi-Purpose Crew Vehicle } \\ M P R V & =\text { Multi Point Random Vibration } \\ M P V & =\text { Master Verification Plan } \\ M S T A & =\text { MPCV Static Test Article } \\ N A S A & =\text { National Aeronautics and Space Association } \\ O \& C & =\text { Neil Armstrong Operations \& Checkout Facility } \\ P A-1 & =\text { Pad Abort }-1 \\ P B S & =\text { Plum Brook Station } \\ R A L & =\text { Reverberant Acoustics Lab } \\ R A T & =\text { Reverberant Acoustics Test } \\ S A J & =\text { Service Adapter Jettisoned } \\ S L S & =\text { Space Launch System } \\ S M & =\text { Service Module } \\ S T A & =\text { Static Test Article } \\ T V A C & =\text { Thermal Vacuum }\end{array}$

\section{Introduction}

$\mathrm{T}$

HE Multiple Purpose Crew Vehicle (MPCV) or Orion program continues to progress in providing a crew transportation vehicle for the NASA Exploration Systems Development (ESD) program to support missions beyond Low Earth Orbit (LEO). The Orion program is developing a human rated spacecraft design and manufacturing and test capability to support the NASA exploration missions using an incremental approach with multiple flight test articles to retire program risk with qualification and flight tests. This paper describes how the Orion program is implementing new and innovative test approaches and strategies in an evolving development environment meeting program test objectives. As each flight test article matures in design and functionality, acceptance and qualification testing approaches are also evolving and maturing to verify the designs and validate acceptance test methods for future production vehicles to meet the challenges of deep space exploration.

A key contributor to a low risk manufacturing and test capability on Orion was the decision to locate the assembly and test operations adjacent to the launch site at KSC. The Neil Armstrong Operations and Checkout Facility (O\&C) as shown in Figure 1 at the Kennedy Space Center (KSC) is the location where the Orion manufacturing and test operations are performed to assemble and test the spacecraft. The O\&C facility was originally established for the Apollo program in the 1960's to support the checkout and integration of the various spacecraft to be integrated on the Saturn V launch vehicle. In 2006 NASA started Orion as part of the Constellation program and initiated the activation of the O\&C facility for spacecraft assembly, integration, and test. The O\&C was selected because as an existing facility it provided a lower cost and more affordable approach versus having to build a new facility. Additionally, its location at KSC eliminated the transportation and checkout risks that would be realized if the spacecraft were manufactured at other locations across the country. 


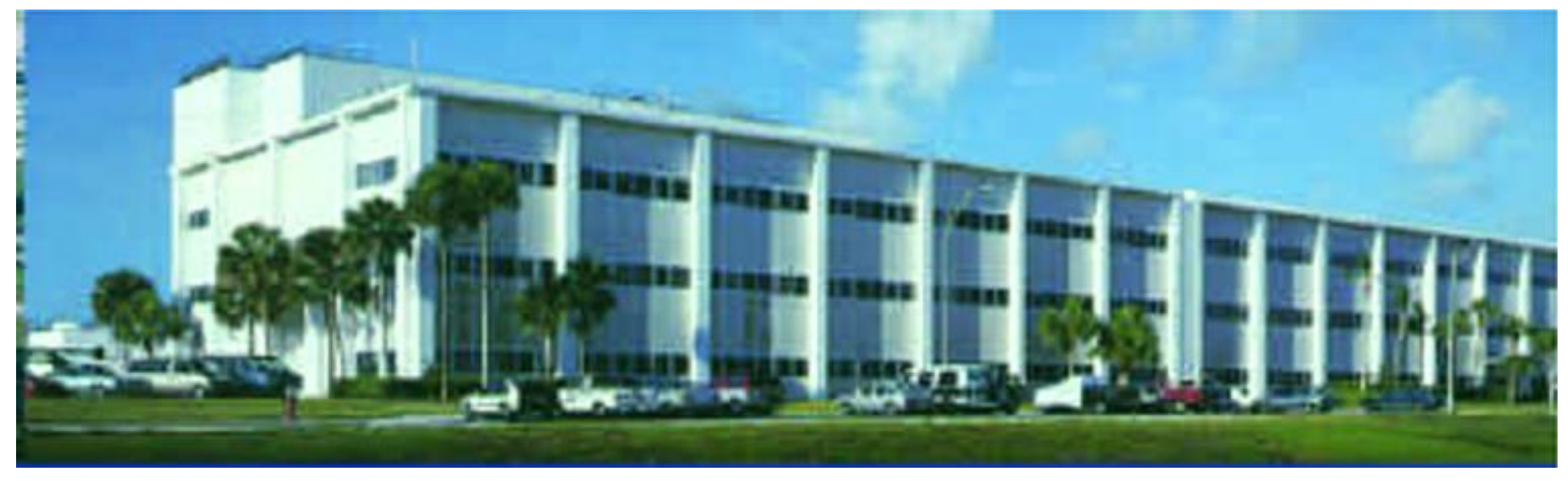

\section{Figure 1 - Neil Armstrong Operations \& Checkout Building (O\&C) at KSC Industrial Area}

The first flight test spacecraft processed in the O\&C was the Exploration Flight Test - 1 (EFT-1) vehicle, which was a 27-month production and test operation ending with the flight test in December 2014. This was the first vehicle to exercise the O\&C manufacturing and test capabilities and was integrated onto the Delta IV heavy launch vehicle at the Cape Canaveral Air Force Station (CCAFS). The EFT-1 flight test duration was a four hour mission that successfully performed the ascent staging of Orion fairings and adapters, the jettison of the Launch Abort System (LAS) and flew two high altitude orbits achieving $80 \%$ of the re-entry heating requirements and safely landed in the Pacific Ocean where recovery operations retrieved the capsule as shown in Figure 2.
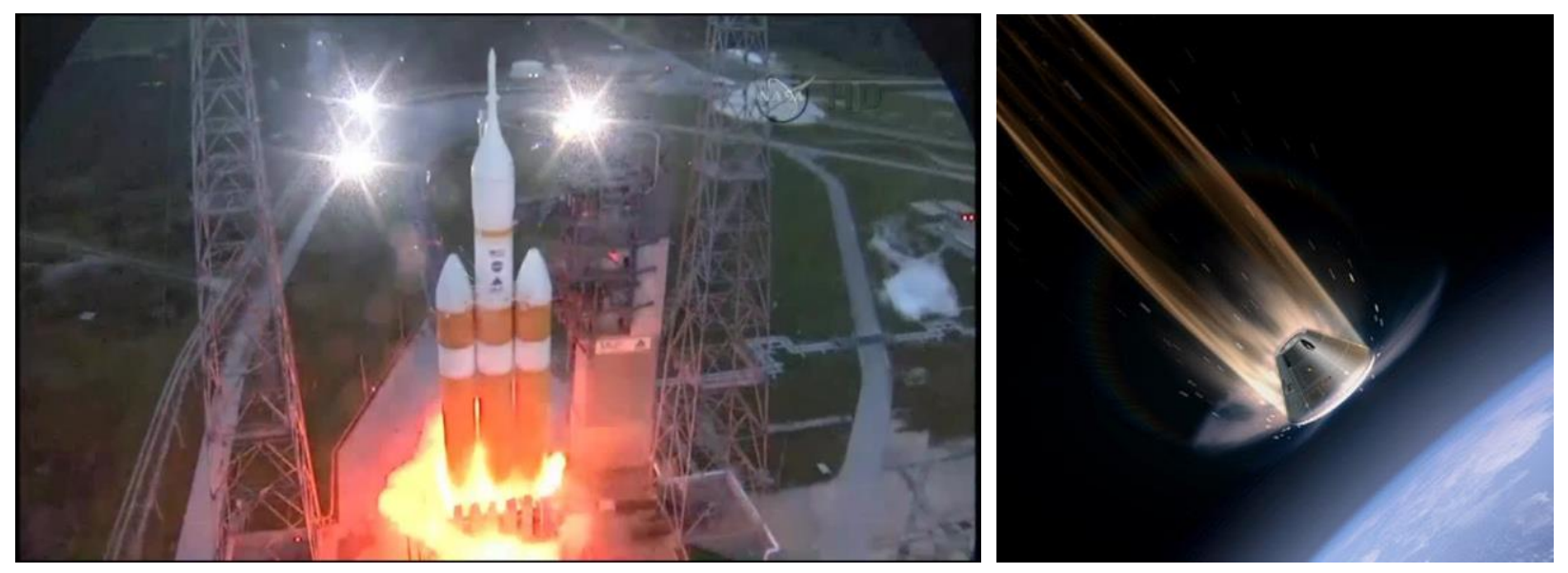

Figure 2 - EFT-1 Launch on Delta IV and Re-Entry of Capsule

As a development flight test article, EFT-1 experienced limited environmental acceptance testing and subsystem functional test and checkout. A static structural acceptance test was performed for the Service Module (SM) primary structure in the high bay of the O\&C and a Multi-Point Random Vibration (MPRV) Test was performed in an adjacent build position for the Crew Module (CM) in the O\&C. The MPRV was used to establish the dynamic characteristics of the CM with installed subsystems. The success of the EFT-1 mission not only validated the engineering design, both hardware and software, but also demonstrated that the manufacturing and test operations established at the O\&C were in place to support the next Orion flight test production needs.

The Exploration Mission - 1 (EM-1) flight test spacecraft is designed and in production to meet the flight test objectives of an unmanned orbital mission to the moon and return to earth in 2019. The spacecraft configuration is summarized in Figure 3 where the CM, Spacecraft Adapter Jettisoned (SAJ), and LAS are derived from the EFT-1 design. EM-1 will require a new propulsion system module and is provided by the European Space Agency (ESA). A European Service Module (ESM) propulsion system will be integrated into the Crew Module Adapter (CMA) to provide the functionality of a Service Module (SM) for the EM-1 spacecraft. 


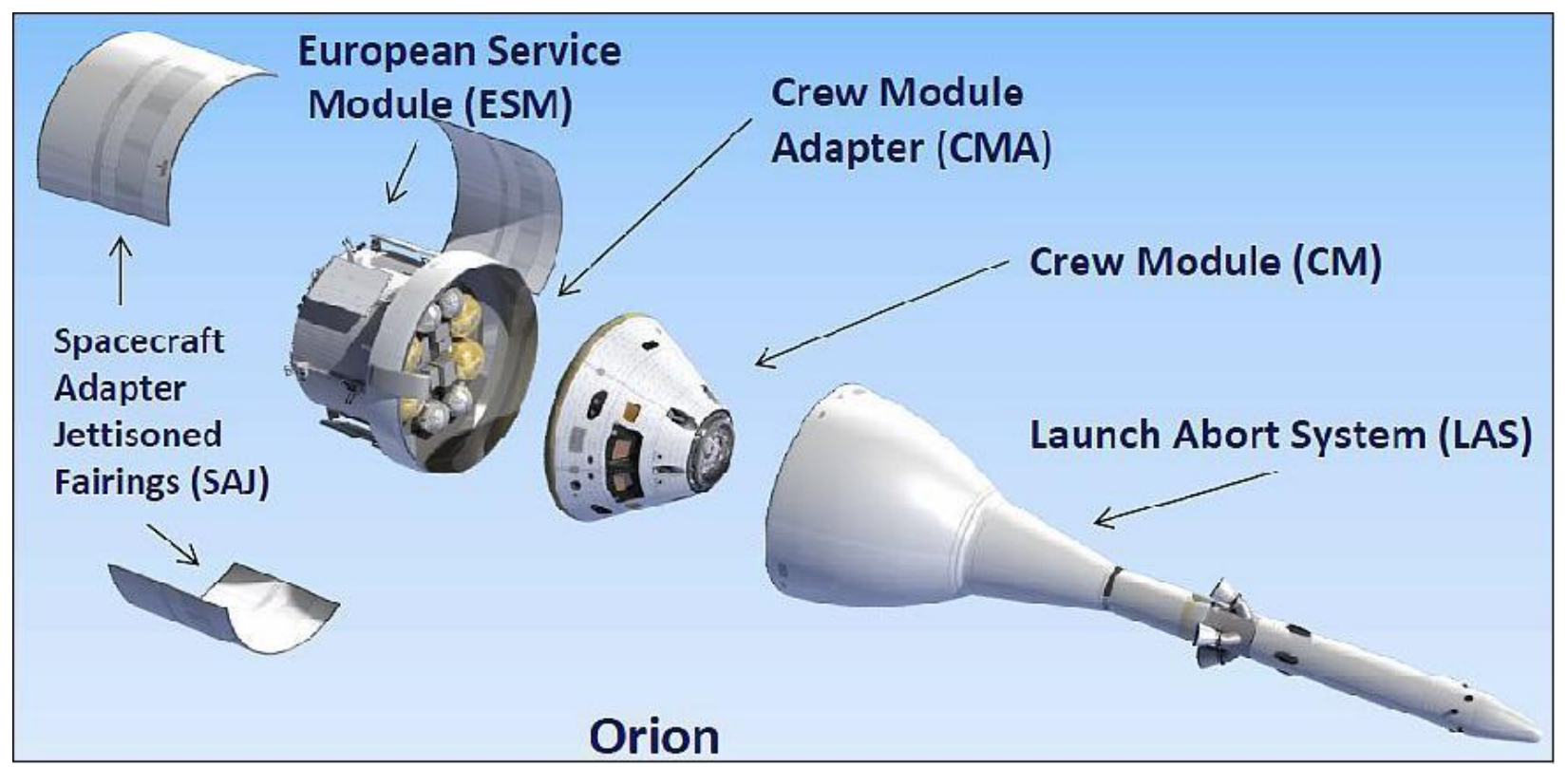

Figure 3 - EM-1 Spacecraft Configuration Overview

The EM-1 spacecraft will be launched by NASA's new Space Launch System (SLS) transportation system which will be the first operational flight for NASA's new launch vehicle. The SLS launch vehicle for the EM-1 mission will use the Block 1 version of SLS containing an Interim Cryogenic Propulsion Stage (ICPS) which will assist Orion to lunar transfer orbit as shown in Figure 4. The EM-1 Orion spacecraft will be tested as both a qualification test article during the manufacturing and test operations as well as a risk reduction flight test article for the EM-1 mission. This dual usage of EM-1 is a key innovation in the MPCV development test strategy to achieving risk reduction while supporting the flight test program.
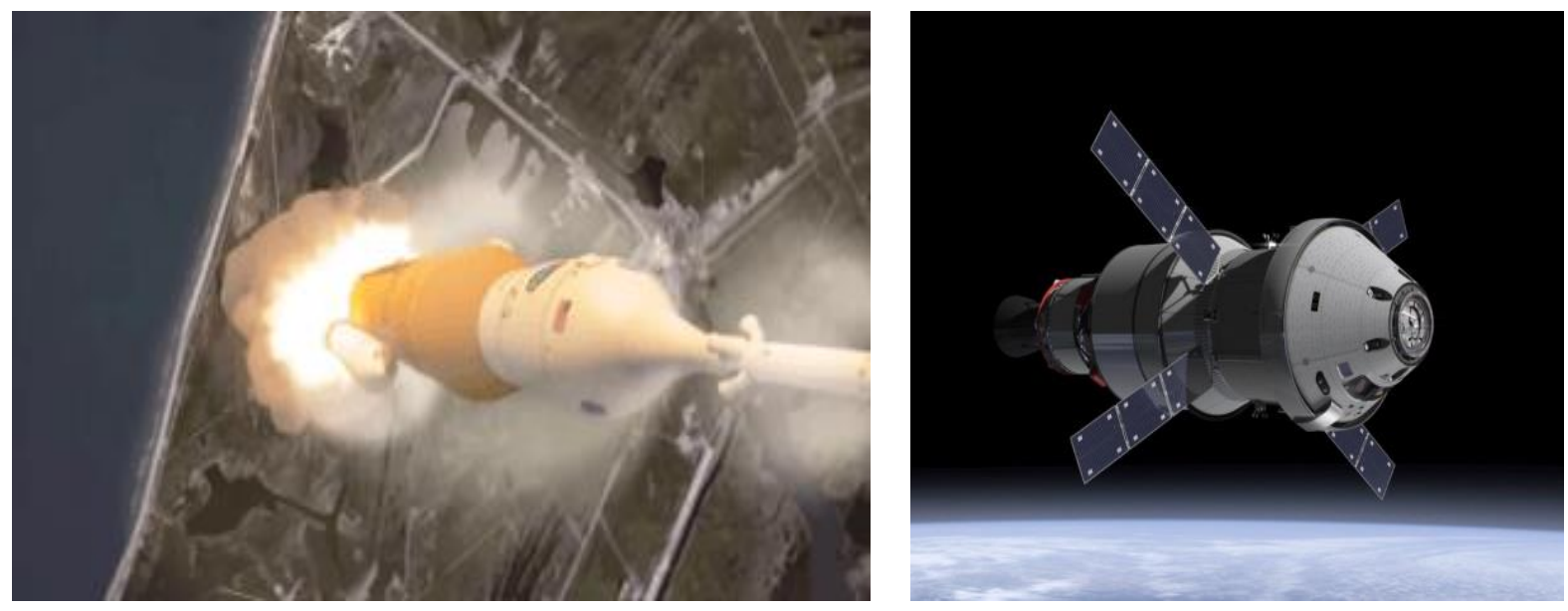

Figure 4 - EM-1 Launch on SLS Launch Vehicle and Lunar Mission On-Orbit Configuration 


\section{MPCV Program Verification Strategy}

The Orion program has been in a development phase since program start in 2006 and experienced a significant programmatic change with the cancelation of the Constellation program in 2010. Orion transitioned to the MPCV program to continue the development of the spacecraft, but at extended program schedule and funding levels. This necessitated considerable changes to the development plans and resulting verification approaches to enable adequate risk reduction to support a crewed flight mission capability. In 2012 the focus of Orion transitioned from a Low Earth Orbit (LEO) mission to a deep space mission and a new program test and verification strategy was developed. This strategy moved away from a traditional dedicated qualification test article approach to a distributed qualification approach with incremental vehicle development. Qualification tests continue to be performed at the Plum Brook Station (PBS) Facility in Ohio for the development verification of the flight vehicle configuration and alternative testing innovations were introduced at the $O \& C$ to support acceptance testing for spacecraft production.

An MPCV Development Test Program Road Map (Figure 5) summarizes the development test articles required to meet the revised verification strategy for both qualification and flight test risk reduction. Flight test articles include the Pad Abort vehicle (PA-1) which flew in 2010 demonstrating the LAS capability for on pad abort, the EFT-1 vehicle which flew in 2014, and the EM-1 vehicle which will fly in 2019. A high Altitude Abort (AA-2) flight test is also planned in 2019 that will validate the LAS abort capabilities at supersonic velocities. Qualification test articles include the MPCV Static Test Article (MSTA), the European Static Test Article (ESTA), and the Environmental Test Article (ETA). The EM-2 vehicle will be the first crewed flight article and will complete the qualification and risk reduction milestones for the development program. The EM-3 vehicle will be the first production spacecraft for the MPCV program. Each test article is configured to meet the test objectives for the qualification and flight test program minimizing the hardware cost for each test. A full functioning MPCV spacecraft is planned for the EM-2 flight test which will be a crewed mission.

The Road Map identifies the MPCV test articles for ground and flight test where the flight test risk reduction vehicles are shown in green and the qualification vehicles are shown in orange. The successful completion of these test milestones supports the verification and validation of the MPCV program providing a human rated crew transportation capability for ESD. A significant feature to the development test strategy is utilizing the EM-1 vehicle as both a qualification and flight risk reduction test article shown in green/orange. Additionally, the returned CM from the EM-1 mission will be incorporated into the ETA test article to support the qualification of MPCV for crew abort capability.

The qualification test program utilizes the PBS test facility to provide system environmental test capability for acoustics and Thermal Vacuum (TVAC) environments. With the MPCV qualification test article manufactured and assembled at the $\mathrm{O} \& \mathrm{C}$ facility at $\mathrm{KSC}$, transportation of the test article is necessary to conduct qualification testing in Ohio and return to KSC for final spacecraft assembly completion and integration to the launch vehicle. This approach introduces risk to the program due to additional processing of the spacecraft to configure for transportation, reassembly at PBS, return back to KSC and checkout the spacecraft for re-integration into the assembly flow in the O\&C. Additional risk is added for contingency assembly operations at PBS to the test article for modifications of the test article for anomalous test result discovery. This risk is acceptable for a one-time qualification test, but not for a recurring production operations for subsequent vehicles. A product from the MPCV program verification strategy established an approach for MPCV production operations to accomplish an acceptance testing approach to mitigate the testing risk of utilizing PBS for recurring testing. One option is to duplicate the test capability of the PBS facilities at KSC which is not practical and a second approach is to consider alternative test methods at KSC to accomplish the acceptance testing in the O\&C facility. Innovative acoustic and thermal/vacuum test methods were established to meet these risk reduction objectives with proof of concept tests and a validation plan added to the MVP to be executed during the qualification program execution.

The Road Map identifies the resulting production acceptance test innovations derived from the distributed and incremental development and verification approach for the MPCV program. Three significant acceptance test methods are validated in this plan which is the Direct Field Acoustics Test (DFAT), the Thermal Cell Test, and an Altitude Chamber Test. These testing methods will be validated and grounded by the qualification test program using reverberant acoustic chamber testing and the Thermal Vacuum (TVAC) environmental testing conducted on

the EM-1 vehicle. Successful implementation of this acceptance test plan will reduce MPCV program risk as the program transitions into the production phase. 


\section{MPCV Development Test Program Road Map}
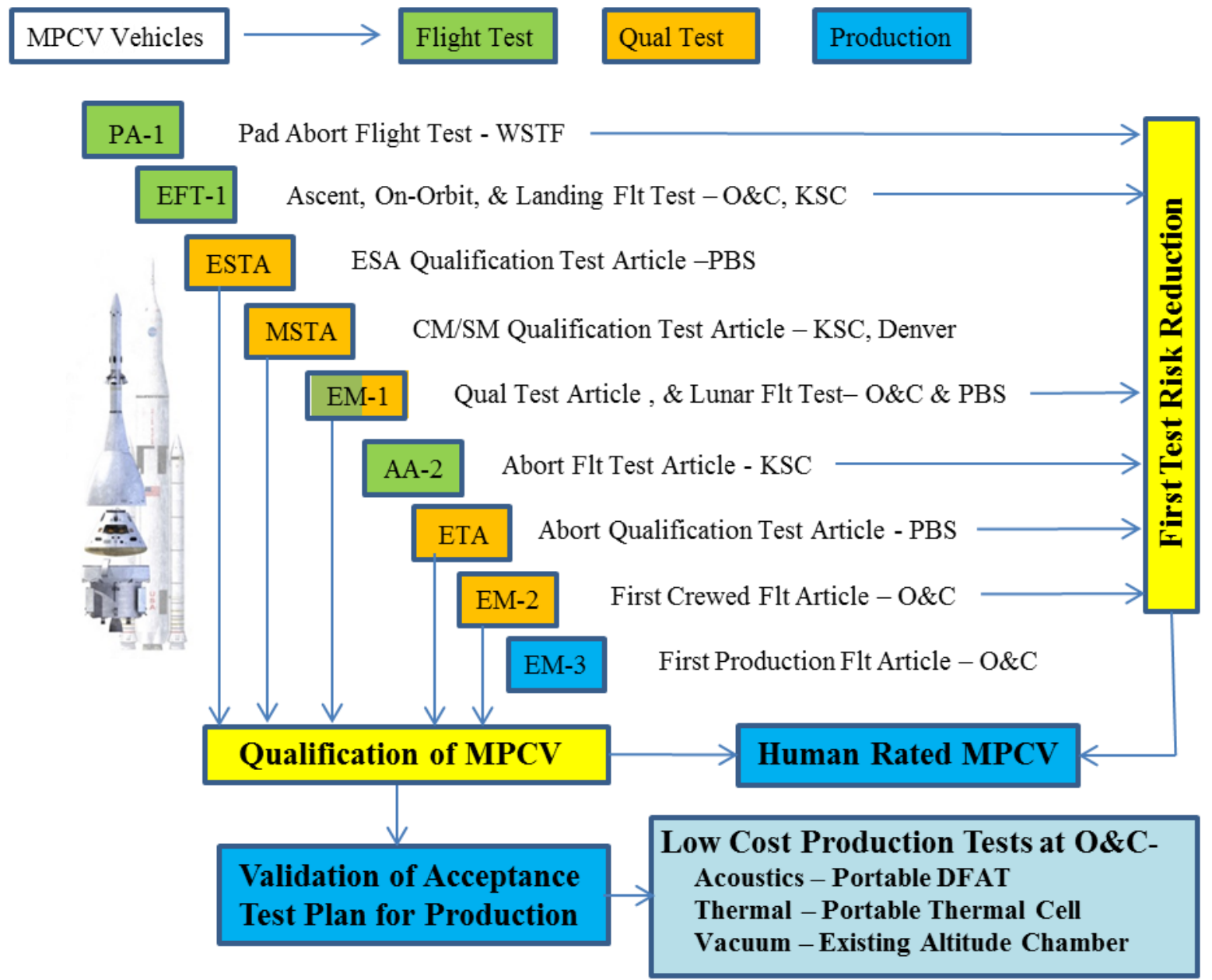

Figure 5 - MPCV Development Test Program Road Map

\section{MPCV Verification Test Evolution}

The MPCV verification program is based on a distributed qualification approach using incremental design configurations leading up to a fully functional spacecraft configuration with critical mission flight risk reduction successes. This approach enabled MPCV to accomplish the system qualification of the spacecraft using multiple test articles incrementally developed over several years. This "build a little, test a little" strategy required the successful completion of several vehicle test milestones which enabled early risk reduction and demonstrated program viability to meet NASA's goals of deep space crewed missions. Key to the risk reduction objectives is successful completion of these critical test milestones established in the MPCV Master Verification Plan (MPV). Table 1 describes the Flight Vehicles test program evolution comparison for critical flight test milestones from the program beginning or Initial Operational Capability (IOC) to completion of the first production vehicle EM-3. System acceptance and qualification testing is identified for each test vehicle and a further breakout of the environmental testing is described for each flight test vehicle. System Qualification is accomplished on EM-1 with testing performed at PBS. 
Highlighted in blue is the innovative acceptance test methods validated for O\&C production operations. The testing approach and methods are evolving as the test articles are maturing resulting in a production acceptance test methodology for EM-3 first production. The following discussions summarize each of the Orion vehicle test approaches:

\begin{tabular}{|c|c|c|c|c|c|c|c|}
\hline \multicolumn{8}{|c|}{ MPCV Flight Vehicles Environmental Test Program Evolution Comparison } \\
\hline $\begin{array}{c}\text { Flight Article } \\
\text { Test Operations }\end{array}$ & $\begin{array}{c}\text { Baseline } \\
\text { IOC } \\
2011\end{array}$ & \begin{tabular}{|c|} 
EFT-1 Vehicle \\
2014
\end{tabular} & \begin{tabular}{|c|} 
EM-1 Vehicle \\
2019
\end{tabular} & $\begin{array}{c}\text { EM-2 } \\
\text { (Crewed Flt) }\end{array}$ & $\begin{array}{c}\text { EM-3+ (Crewed } \\
\text { Flt })\end{array}$ & Comments & Benefits \\
\hline Program Type & DDT\&E & DDT\&E & DDT\&E & DDT\&E & Production & & \\
\hline $\begin{array}{c}\text { System } \\
\text { Acceptance } \\
\text { Testing }\end{array}$ & $\begin{array}{c}\text { Testing } \\
\text { Planned at } \\
\text { PBS }\end{array}$ & $\begin{array}{l}\text { O\&C- Limited } \\
\text { Testing for } \\
\text { Static, } \\
\text { Dynamic, \& } \\
\text { EMI/EMC }\end{array}$ & $\begin{array}{c}\text { O\&C- Testing } \\
\text { for Acoustics, } \\
\text { Thermal }\end{array}$ & $\begin{array}{c}\text { O\&C- Testing } \\
\text { for Acoustics, } \\
\text { Thermal, } \\
\text { Vacuum, } \\
\text { EMI/EMC }\end{array}$ & $\begin{array}{c}\text { O\&C- Testing } \\
\text { for Acoustics, } \\
\text { Thermal, } \\
\text { Vacuum }\end{array}$ & $\begin{array}{c}\text { Evolving Test } \\
\text { Operations } \\
\text { Transition to } \\
\text { O\&C } \\
\text { Production Ops }\end{array}$ & $\begin{array}{c}\text { Eliminates } \\
\text { Transportation } \\
\text { of Spacecraft or } \\
\text { New facilities for } \\
\text { Acceptance } \\
\text { Testing }\end{array}$ \\
\hline $\begin{array}{c}\text { System } \\
\text { Qualification } \\
\text { Testing }\end{array}$ & \begin{tabular}{|c|} 
Testing \\
Planned at \\
PBS with \\
dedicated \\
Qual Vehicle
\end{tabular} & NA & \begin{tabular}{|c|} 
PBS- \\
Transport CSM \\
for Testing for \\
TVAC, \\
Acoustics \& \\
EMI/EMC
\end{tabular} & NA & NA & $\begin{array}{c}\text { Qualification } \\
\text { results from } \\
\text { EM-1 Tests } \\
\text { Validate } \\
\text { Acceptance } \\
\text { Test Approach }\end{array}$ & $\begin{array}{l}\text { Use PBS for } \\
\text { Qualifaction } \\
\text { Testing During } \\
\text { DDT\&E for } \\
\text { Orion and ESD } \\
\text { Vehicles }\end{array}$ \\
\hline \multicolumn{8}{|l|}{$\begin{array}{c}\text { Environment } \\
\text { Testing } \\
\end{array}$} \\
\hline Static Structural & MAF & $\begin{array}{l}\text { SM Test in } \\
\text { Aisle }\end{array}$ & $\begin{array}{c}\text { STA Tested } \\
\text { offline in } \\
\text { Denver }\end{array}$ & NA & NA & $\begin{array}{l}\text { No Test for } \\
\text { Production }\end{array}$ & $\begin{array}{c}\text { No Impact to } \\
\text { O\&C }\end{array}$ \\
\hline $\begin{array}{c}\text { Nominal } \\
\text { Vibration }\end{array}$ & PBS & $\begin{array}{l}\text { CM MPRV in } \\
\text { Temp Station }\end{array}$ & NA & NA & NA & $\begin{array}{l}\text { No Test for } \\
\text { Production }\end{array}$ & $\begin{array}{c}\text { No Impact to } \\
\text { O\&C }\end{array}$ \\
\hline Acoustics & PBS & $\begin{array}{c}\text { DFAT Proof of } \\
\text { concept }\end{array}$ & $\begin{array}{c}\text { CM \& SM } \\
\text { DFAT in Temp } \\
\text { Station }\end{array}$ & $\begin{array}{c}\text { CM \& SM } \\
\text { DFAT in Temp } \\
\text { Station }\end{array}$ & $\begin{array}{c}\text { CM \& SM } \\
\text { DFAT in Temp } \\
\text { Station }\end{array}$ & $\begin{array}{l}\text { Portable DFAT } \\
\text { in O\&C }\end{array}$ & $\begin{array}{l}\text { Portable Test } \\
\text { Setup } \\
\text { No Impact to } \\
\text { O\&C }\end{array}$ \\
\hline Thermal Cycle & PBS & NA & $\begin{array}{c}\text { CM \& SM } \\
\text { Using Thermal } \\
\text { Cell }\end{array}$ & $\begin{array}{c}\text { CM \& SM } \\
\text { Using Thermal } \\
\text { Cell }\end{array}$ & $\begin{array}{c}\text { CM \& SM } \\
\text { Using Thermal } \\
\text { Cell }\end{array}$ & $\begin{array}{l}\text { Reconfigurable } \\
\text { Thermal Cell in } \\
\text { O\&C }\end{array}$ & $\begin{array}{l}\text { New Thermal } \\
\text { Cell in the O\&C ( } \\
\text { ECD July 2017) }\end{array}$ \\
\hline $\begin{array}{l}\text { High Altitude } \\
\text { Vacuum }\end{array}$ & PBS & NA & NA & $\begin{array}{l}\text { CSM Using } \\
\text { Altitude } \\
\text { Chamber }\end{array}$ & $\begin{array}{l}\text { CSM Using } \\
\text { Altitude } \\
\text { Chamber }\end{array}$ & $\begin{array}{c}\text { Refurbish } \\
\text { Altitude } \\
\text { Chamber in } \\
\text { O\&C } \\
\end{array}$ & $\begin{array}{c}\text { Use Existing Alt } \\
\text { Chamber } \\
\text { No Impact to } \\
\text { O\&C } \\
\end{array}$ \\
\hline TVAC & PBS & NA & $\begin{array}{l}\text { Qualification } \\
\text { Testing for } \\
\text { CSM at PBS }\end{array}$ & NA & NA & $\begin{array}{c}\text { Qualification } \\
\text { Tests Only at } \\
\text { PBS }\end{array}$ & $\begin{array}{l}\text { No Impact to } \\
\text { O\&C }\end{array}$ \\
\hline EMI/EMC & PBS & $\begin{array}{c}\text { CSM in Fast } \\
\text { Cell }\end{array}$ & $\begin{array}{l}\text { Qualification } \\
\text { Testing for } \\
\text { CSM at PBS }\end{array}$ & $\begin{array}{c}\text { CSM in Fast } \\
\text { Cell }\end{array}$ & NA & $\begin{array}{l}\text { No Test for } \\
\text { Production }\end{array}$ & $\begin{array}{c}\text { No Impact to } \\
\text { O\&C }\end{array}$ \\
\hline
\end{tabular}

Table-1- MPCV Flight Vehicles Environmental Test Program Evolution Comparison 


\section{A. Baseline MPCV IOC 2011-}

The baseline MPCV program plans were based on production of the flight spacecraft located at the O\&C at KSC and the system level acceptance and qualification conducted at the PBS located near Glenn Research Center located in Ohio. Facility upgrades were invested in both locations to modernize and stand up capabilities for NASA's Constellation next generation space program. Both of the NASA Centers have support infrastructure in place to support manufacturing and test operations with facilities, equipment and work force to support the MPCV program objectives. The challenge with this approach was the transportation of the completed spacecraft from KSC to PBS and back to KSC for system acceptance testing. This introduced program risk and schedule impacts to the program. Structural testing was also planned at the Michoud Assembly Facility (MAF) in Louisiana where the CM and SM primary structure was fabricated and delivered O\&C.

\section{B. EFT-1 Flight Test 2014-}

The MPCV program established an early vehicle flight test milestone to demonstrate launch, ascent, on-orbit, reentry, and landing capabilities of the Orion spacecraft. This flight test milestone required the program to execute engineering, manufacturing and operations capability to provide a spacecraft to perform the mission functionality as a risk reduction milestone. EFT-1 spacecraft was developed and launched in 3 years using a concurrent approach with design, procurement, and assembly operations performing in a streamlined execution approach with minimum vehicle testing performed. This milestone exercised the program elements of engineering, procurement, manufacturing, and spacecraft integration onto a launch vehicle. Selected acceptance test were performed on the CM using the MPRV technique and a static structural test of the SM was conducted in the O\&C as part of the assembly operations.

\section{EM-1 Flight Test 2019-}

The MPCV program established the baseline engineering design for EM-1 to be used as the qualification test article and also as a flight article for the first launch of NASA's SLS launch system. This vehicle is executed as a human rated vehicle with operational capability to support a lunar mission, but un-crewed. Supporting static test articles are included in this milestone both for the CM, MSTA, and SM, ESTA for qualification testing at the module level. The assembled EM-1 spacecraft is transported to PBS for TVAC testing and returned to KSC for integration onto SLS. Module level acceptance test methods are validated on EM-1 and are used in the O\&C for acceptance in subsequent vehicles avoiding transportation cost and schedule in the future.

\section{EM-2 Flight Test (First Crewed Flight)-}

The MPCV test program established the first crewed mission for the program with EM-2 which will utilize the qualification and risk reduction experience from EM-1 with selected additional verification of crew systems to complete the spacecraft qualification for crewed flight.

\section{E. EM-3+ Flight (First Production)-}

The MPCV program transitions into full production with the completion of EM-3. Flight test results from EM-2 will be incorporated into the EM-3 spacecraft which will complete the certification of MPCV for human rating.

The operational benefits to the O\&C facility to support acceptance testing for production as a result of the MPCV evolutionary approach are summarized in the last column in Table 1. The implementation of the three test capabilities for acceptance testing for a DFAT position, a Thermal Cell position, and use of the existing Altitude chamber in the $\mathrm{O} \& \mathrm{C}$ have minimal impact to the existing operations of the $\mathrm{O} \& \mathrm{C}$ manufacturing and assembly operations. This results in a reduction in program risk with a seamless manufacturing and test operations for the MPCV program at the KSC launch site. This capability is enabled by the innovative test methods for acoustics and thermal/vacuum testing summarized in the following sections. 


\section{MPCV Acoustics Testing}

Acoustics testing simulates the severe dynamic environments the MPCV spacecraft experience during mission phases from launch through landing. The MPCV MVP requires acoustics testing for qualification and acceptance of the spacecraft. Traditional methods utilize an acoustic reverberant test chamber to simulate the dynamic environments of the spacecraft mission for qualification and acceptance testing. Reverberant chambers exist in a variety of locations in the aerospace community including Lockheed Martin Space Systems Company (LM) in Denver, Colorado and at the PBS in Ohio, but not at KSC. An alternative approach to reverberant acoustics testing is using an alternative method called Direct Field Acoustic Test (DFAT) which utilizes a portable test setup around the test article. The MPCV program developed an approach to utilize both reverberant chambers for qualification and DFAT approach to conduct acceptance testing resulting in a validated acceptance approach in the O\&C. The reverberant chambers can achieve sound pressure levels for qualification, but the DFAT approach can only achieve sound pressure levels necessary for acceptance.

The MPCV program has conducted acoustic test correlation assessments for reverberant and DFAT methods using existing flight test and development articles as described in Figure 6. The returned CM from the EFT-1 mission was subjected to acoustic testing comparisons for both the DFAT and reverberant testing at LM to establish a proof of concept approach for use of DFAT on the MPCV program.

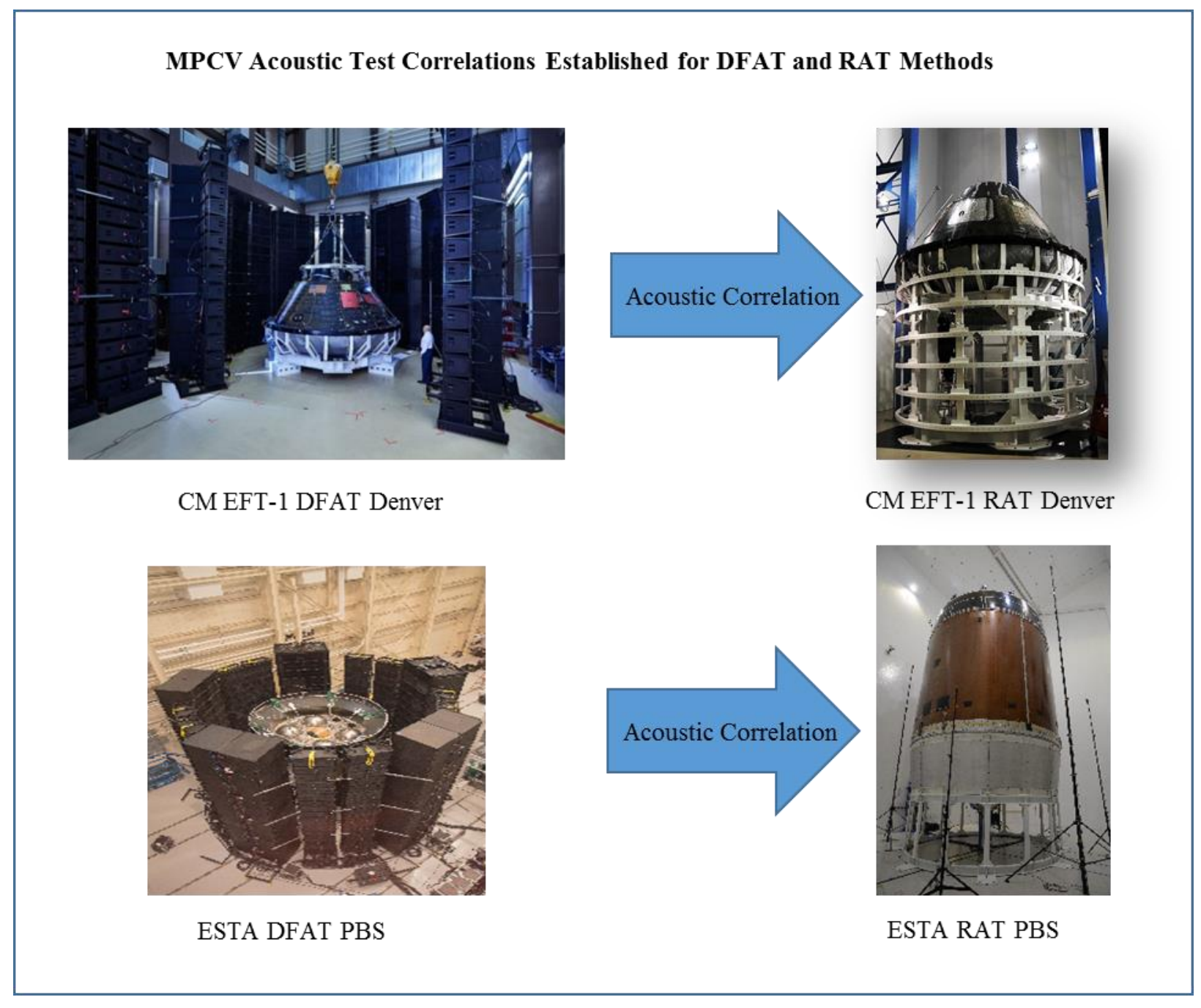

Figure-6- MPCV Acoustic Test Correlations Established for DFAT and RAT Methods 
Acoustic correlation results for DFAT and reverberation methods were acceptable for the CM vehicle configuration. Similar acoustic test comparisons were also conducted on the ESTA test article in PBS with acceptable results. Figure 6 describes the test configurations for the DFAT and Reverberant Acoustics Tests (RAT) conducted at LM Reverberant Acoutics Lab (RAL) in Colorado and at the PBS in Ohio.

The MPCV acoustics qualification and acceptance test approach is summarized in Table 2 which describes the test article configurations, DFAT and reverberant test methods, the location of testing, and testing levels for proof of concept, qualification (nominal and abort flight conditions) and acceptance. Proof of concept correlation testing comparisons are shown in green for the CM (EFT-1) and SM configurations.

The MSTA acoustic test configuration will be a mated CM and SM vehicle with a qualification reverberant testing conducted for EM-1 atLM in Denver. The EM-1 flight test article will experience acceptance testing using DFAT at the O\&C at the module level which will support the validation of acceptance results for EM-2 and production shown in blue. The ETA will be tested at PBS for the abort qualification in support of the AA-2 abort flight test.

This validation will enable MPCV acoustics test operations to support production operations in the O\&C at KSC. Additionally, spacecraft vehicle corrections due to anomolous acoustic test results discovered during these tests can be rapidly implemented since the vehicle is located where the vehicle manufacturing and assembly operations are performed at the $\mathrm{O} \& \mathrm{C}$ reducing risk to the program.

\begin{tabular}{|l|l|l|l|c|}
\hline MPCV Acoustic Verification and Acceptance Approach & \multicolumn{1}{|c|}{ DFAT } & $\begin{array}{c}\text { Environment } \\
\text { Level }\end{array}$ \\
\hline Flight / Test Article & \multicolumn{1}{|c|}{ Module } & \multicolumn{1}{|c|}{ Reverberation } & Yes- Denver & Proof of Concept \\
\hline \multirow{2}{*}{ EFT-1 (Post Flight) } & CM & Yes- Denver & Yes- PBS & $\begin{array}{c}\text { Proof of Concept } \\
\text { \& Nominal Qual }\end{array}$ \\
\hline \multirow{2}{*}{ ESTA } & SM & Yes- PBS & NA & Nominal Qual \\
\hline \multirow{2}{*}{ MSTA } & Stacked CM/SM & Yes- Denver & Yes- O\&C & $\begin{array}{c}\text { Validate } \\
\text { Acceptance }\end{array}$ \\
\hline \multirow{2}{*}{ EM-1/2 } & CM & NA & Yes- O\&C & $\begin{array}{c}\text { Validate } \\
\text { Acceptance }\end{array}$ \\
\cline { 2 - 5 } & SM & NA & NA & Abort Qual \\
\hline \multirow{2}{*}{ ETA } & CM EM-1 (Post Flight) & Yes- PBS & NA & Abort Qual \\
\cline { 2 - 5 } & LAV & Yes- PBS & Yes- O\&C & Acceptance \\
\cline { 2 - 5 } & CM & NA & Yes- O\&C & Acceptance \\
\hline
\end{tabular}

Table-2 - MPCV Acoustic Qualification and Acceptance Test Approach

\section{MPCV Thermal Vacuum Testing}

Thermal vacuum testing simulates the severe temperature and vacuum environments the MPCV spacecraft experience during on-orbit mission phases. The MPCV MVP requires thermal and vacuum testing for qualification and acceptance of the spacecraft. Traditional methods utilize a TVAC test chamber to simulate these environments on the spacecraft. TVAC chambers exist in a variety of locations in the aerospace community including LM Denver, Colorado and PBS in Ohio, but not at KSC. The MPCV program will utilize the TVAC test capability at PBS for qualification of the flight design on EM-1. An alternative approach to TVAC testing for acceptance testing is using an innovative test strategy of conducting a thermal acceptance test and a vacuum acceptance test separately. The MPCV program has developed an approach to conduct acceptance testing at the O\&C using a reconfigurable 
thermal test cell and the existing altitude chamber to meet the requirements in the MVP using results from the TVAC qualification test program. This approach will be validated during the qualification of EM- 1 .

The MPCV program will conduct TVAC testing for qualification testing of the EM-1 at the PBS test facility in Ohio as shown in Figure 7. The EM-1 assembly and test plans include transportation of the spacecraft from the $\mathrm{O} \& \mathrm{C}$ at KSC to the PBS test facility and return to KSC for final spacecraft assembly operations. Figure 8 is a Computer Aided Design (CAD) representation of EM-1 in the PBS TVAC chamber during the test operations and the loading of the NASA Super Guppy of a spacecraft to the test location.

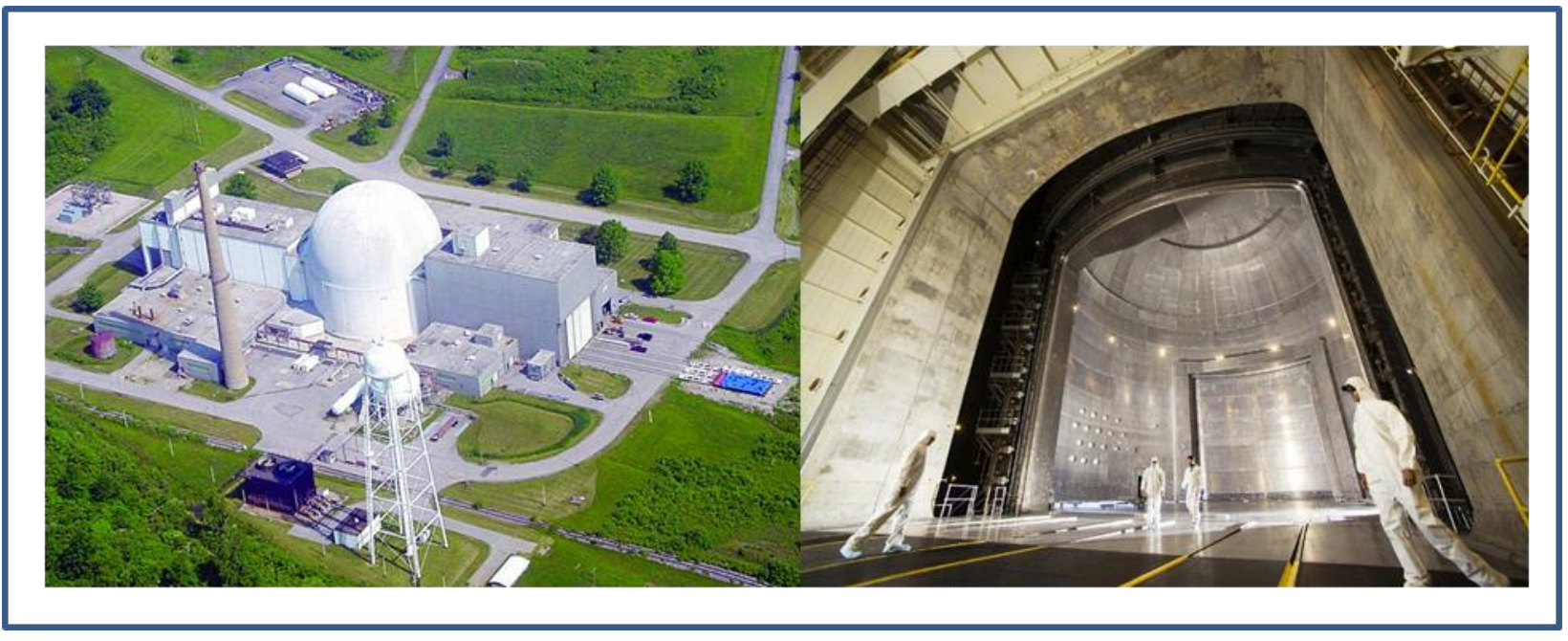

Figure-7- Plum Brook Station Test facility and a view of the TVAC Chamber

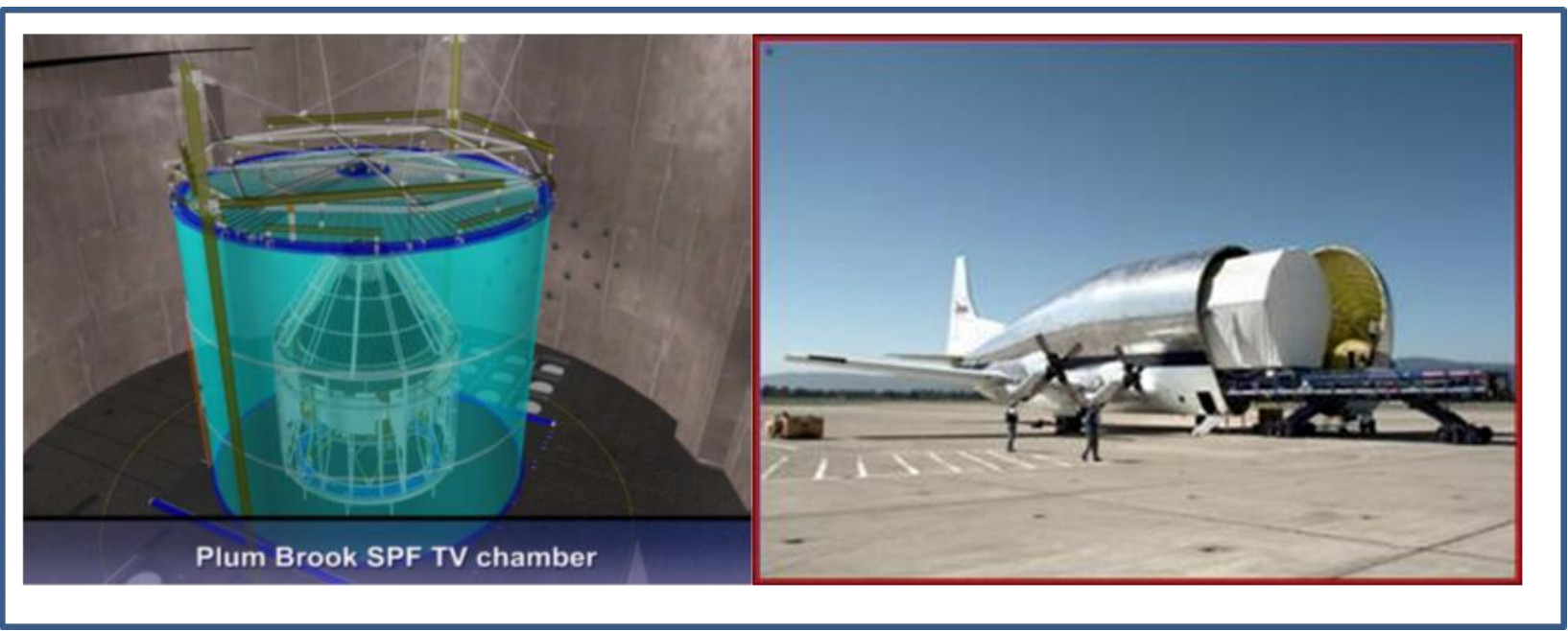

Figure-8- EM-1 Test configuration CAD Model Located in PBS and NASA Super Guppy Transporter

Once the qualification test is successfully completed for the MPCV spacecraft, subsequent MPCV vehicles acceptance tests are at the O\&C at KSC. This approach reduces the risks to the spacecraft for transportation to PBS and return for MPCV production spacecraft for EM-2 and up.

A reconfigurable thermal test cell has been developed and installed in the $\mathrm{O} \& \mathrm{C}$ facility to support the acceptance test plans for MPCV production operations and will be utilized on the EM-1 spacecraft at the module level for the CM and SM modules before transportation to PBS for qualification testing. The test results will ground the module acceptance test strategy with the qualification testing to validate the acceptance process for future production spacecraft. Figure 9 describes the thermal test cell located in the O\&C high bay airlock with the CM postioned on a 
transportation pallet and the supporting thermal test equipment located permanently below in the O\&C basement. This approach enables floor space flexibility as the test cell can be temporaily removed to support other operations as necessary while not impacting the installed support equipment in the basement.

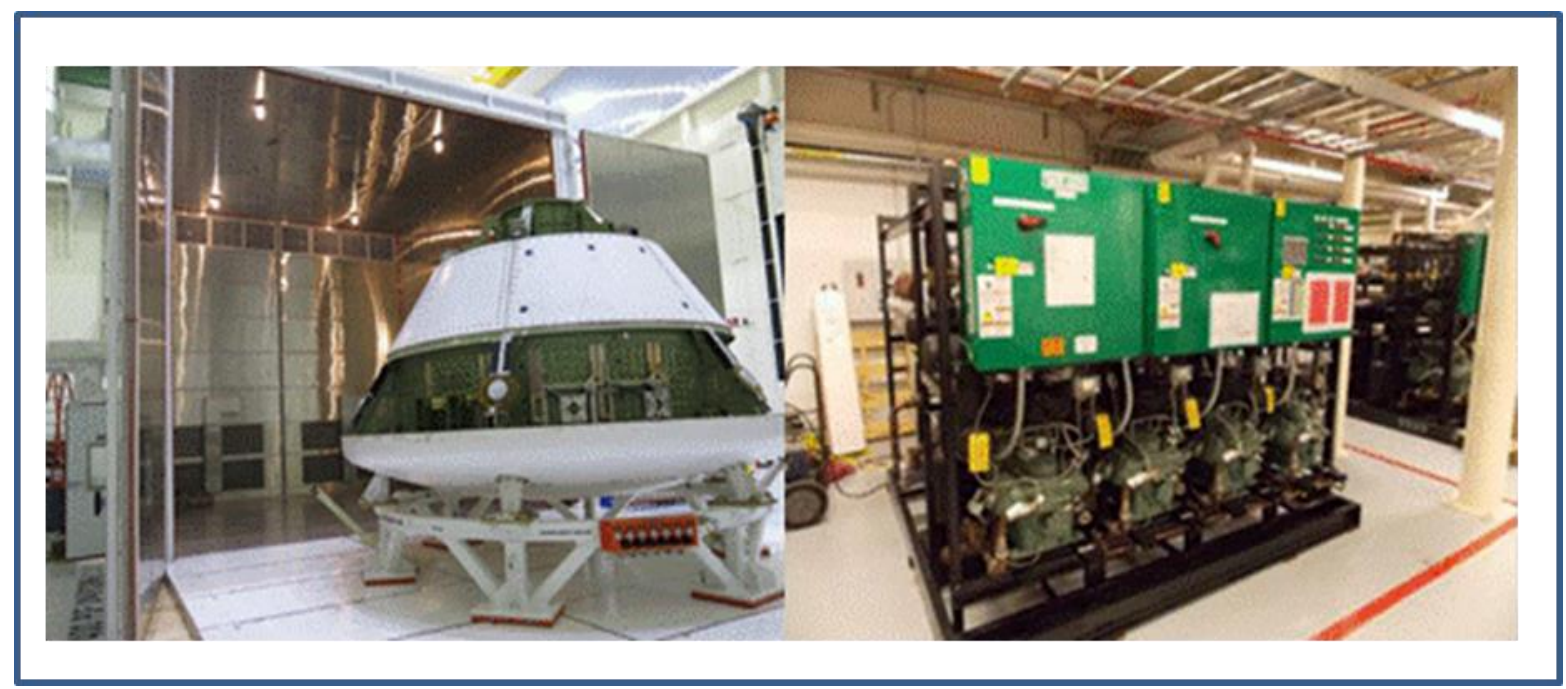

\section{Figure-9- Thermal Cell in the Airlock and the Cell Support Equipment located in the O\&C Basement}

The O\&C high bay has preserved one of the two altitude chambers from the Apollo program and the West chamber will be reactivated for EM-2 to support vacuum testing for the MPCV program. Vacuum acceptance testing of the mated CM/SM configuration will be performed after the module thermal cell acceptance tests are completed. Minimum impact to the assembly and test operations is achieved with the thermal cycle and vacuum tests completed within the O\&C facility. Figure 10 describes the location the altitude chambers in the O\&C high bay and a Computer Aided Design (CAD) Model of Orion installed in the chamber..

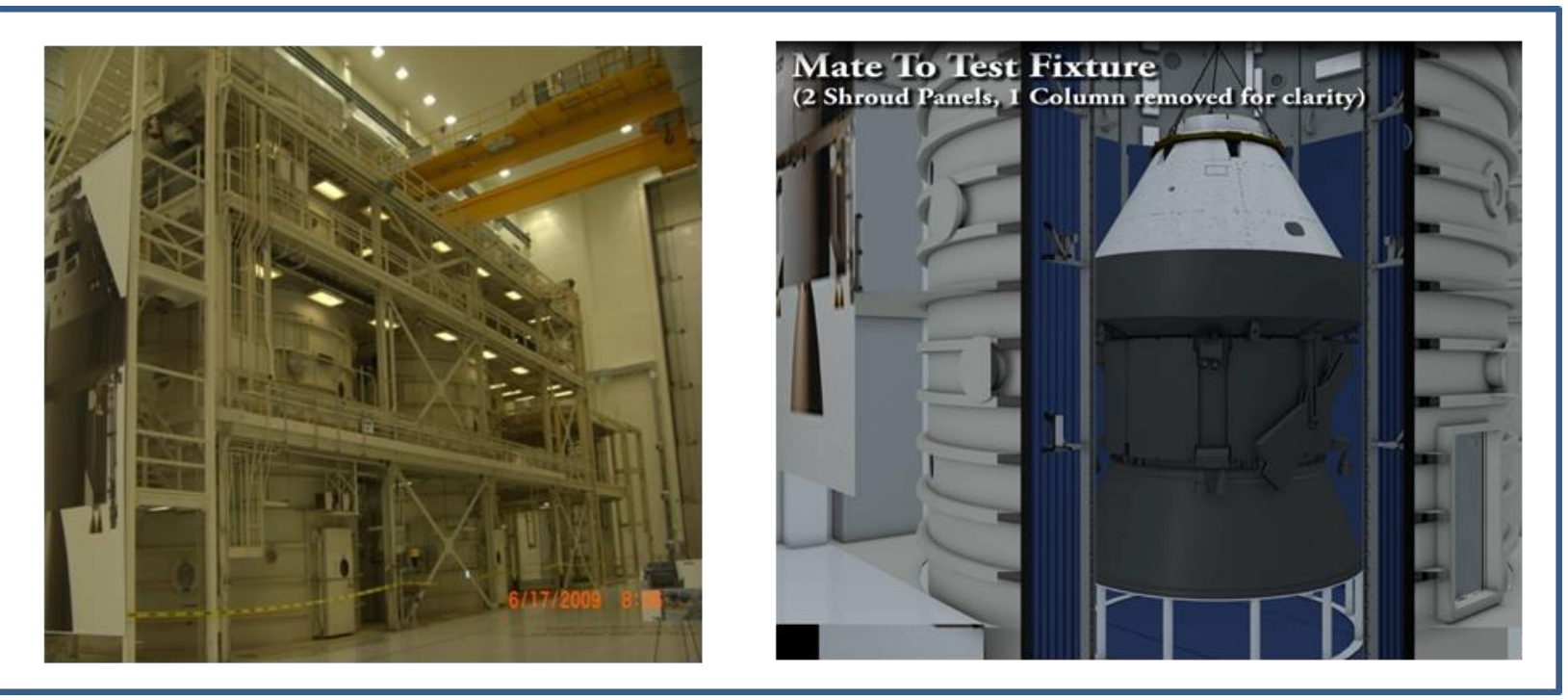

\section{Figure-10- O\&C Altitude Chambers in the High Bay with CAD Model Installed in Test Chamber}

The MPCV thermal qualification and acceptance test approach is summarized in Table 3 which describes the test article configurations, thermal and vacuum test methods, the location of testing, and testing levels for qualification and acceptance. Proof of concept correlation testing comparisons are shown in green for the EM-1 CM, SM, and mated CM/SM configurations. EM-1 thermal cycle testing will be performed at the O\&C at the module level before 
the spaceacraft is mated and tranported to PBS and the mated CM/SM vehicle at PBS will be tested for thermal and vacuum and TVAC conditions to provide qualification tests results and validate the acceptance process for separate thermal cycle and vacuum seperately as shown in green. Subsequent acceptance testing for EM-2 and up will be performed at the O\&C for module level and mated configurations as shown in blue.

\begin{tabular}{|l|l|l|l|l|c|}
\hline MPCV Thermal Qualification and Acceptance Approach & & TVAC & $\begin{array}{c}\text { Environment } \\
\text { Level }\end{array}$ \\
\hline Flight / Test Article & \multicolumn{1}{|c|}{ Module } & Thermal Cycle & Ambient Pressure & Validate \\
& CM & Yes- O\&C & NA & NA & Aceptance \\
\cline { 2 - 6 } & SM & Yes- O\&C & NA & NA & $\begin{array}{c}\text { Validate } \\
\text { Acceptance }\end{array}$ \\
\cline { 2 - 7 } & Mated CM/SM & Yes- PBS & Yes- PBS & Yes- PBS & Qualification \\
\hline \multirow{2}{*}{ EM-3 + (Production) } & CM & Yes- O\&C & NA & NA & Acceptance \\
\cline { 2 - 7 } & SM & Yes- O\&C & NA & NA & Acceptance \\
\cline { 2 - 6 } & Mated CM/SM & NA & Yes- O\&C & NA & Acceptance \\
\hline
\end{tabular}

Table-3- MPCV Thermal Qualification and Acceptance Approach

Similarly to the DFAT test benefits to Orion, the thermal/vacuum test approach validation will support the MPCV test operations to support production operations in the O\&C at KSC. Additionally, spacecraft vehicle corrections due to anomolous thermal/vacuum test results discovered during these tests can be rapidly implemented since the vehicle is located where the vehicle manufacturing and assembly operations are performed at the O\&C reducing program risks.

Implementation of the production system test capabilites described for acoustics and thermal vacuum testing of the MPCV spacecraft in the O\&C facility have minimal impact to the floor operations for spacecraft manufacturing and assembly operations as shown in Figure 11. The portable DFAT acoustics testing can be performed in the transfer aisle across from the final assembly station at the East end of the building. Standard utility provisions already exist and the test setup, execution and deconfigration can be perfomed within the existing program schedule. The Thermal cell is located in the Airlock position at the West end of the building where the cell is postioned to accept a CM and SM module when available for testing within the existing program schedule. Installation of the thermal cell have been completed in 2017 to support the EM-1 testing requirements. The existing West altitude chamber can be loaded with the mated CM/SM using the existing crane in the high bay within the existing program schedule. The activation of the Altitude chamber will be completed to support the EM-2 program. The additional systems test capabilities for MPCV production have minimal impact to the O\&C manufacturing operations within the existing floor space.

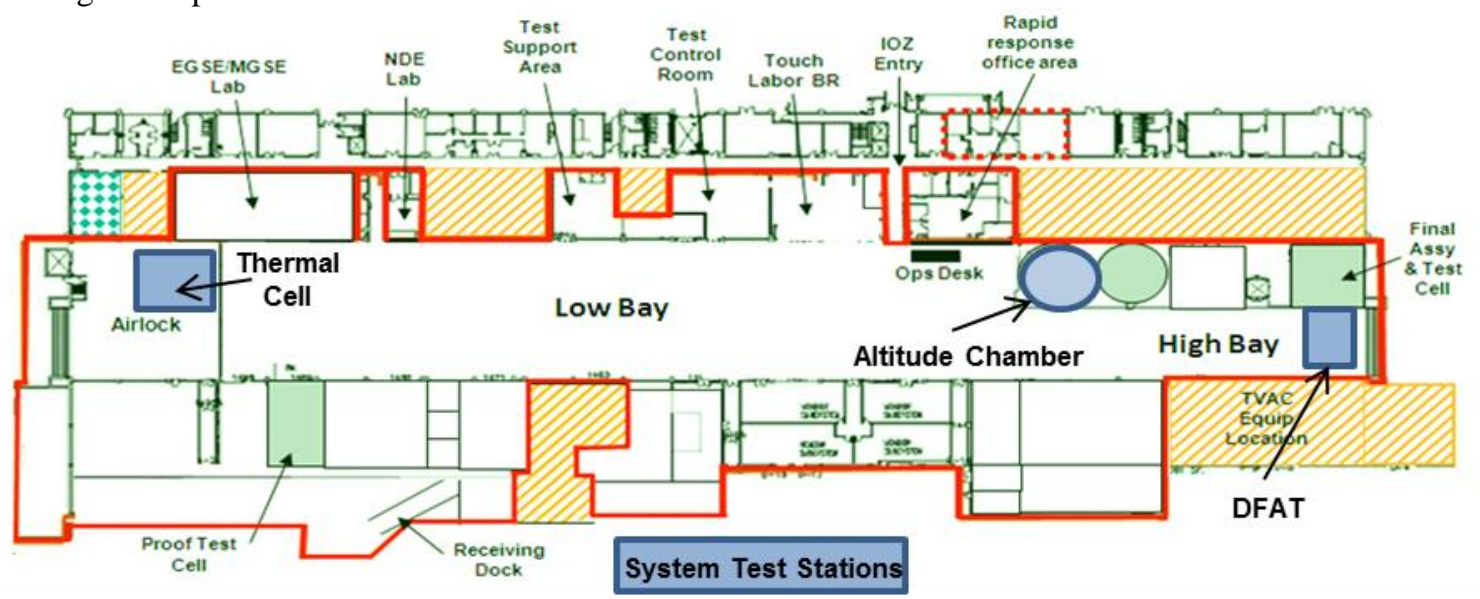

Figure-11- O\&C Floor Layout identifying the locations for System Acceptance Test Positions 


\section{Applicability to Future Vehicles}

The MPCV vehicles are planned to support the Deep Space Gateway (DSG) missions as part of the NASA Exploration Systems Development (ESD) program. The manufacturing and test operations methods and processes developed for the MPCV are applicable to other spacecraft elements such as habitation, logistics, and airlock modules that support the DSG missions as described in the configuration concept in Figure 12. The necessity for affordability on the MPCV program stems from the funding levels being significantly lower than previously experienced on programs such as Apollo or the Space Shuttle. Cost estimates for future manned missions are considerable for Mars exploration missions. Their affordability is enhanced if MPCV cost can be kept to a minimum. Additionally, manufacturing and test operations innovations developed on MPCV can be directly transferred to the DSG vehicles to extend affordability across the mission elements. Key test operations innovations include acoustic, thermal, and vacuum system test approaches located where the spacecraft manufacturing and assembly is performed at KSC. This enables improvements in affordability of the DSG vehicles using a seamless concept of operations from build, assembly, test and launch vehicle integration at one location to support future ESD missions.

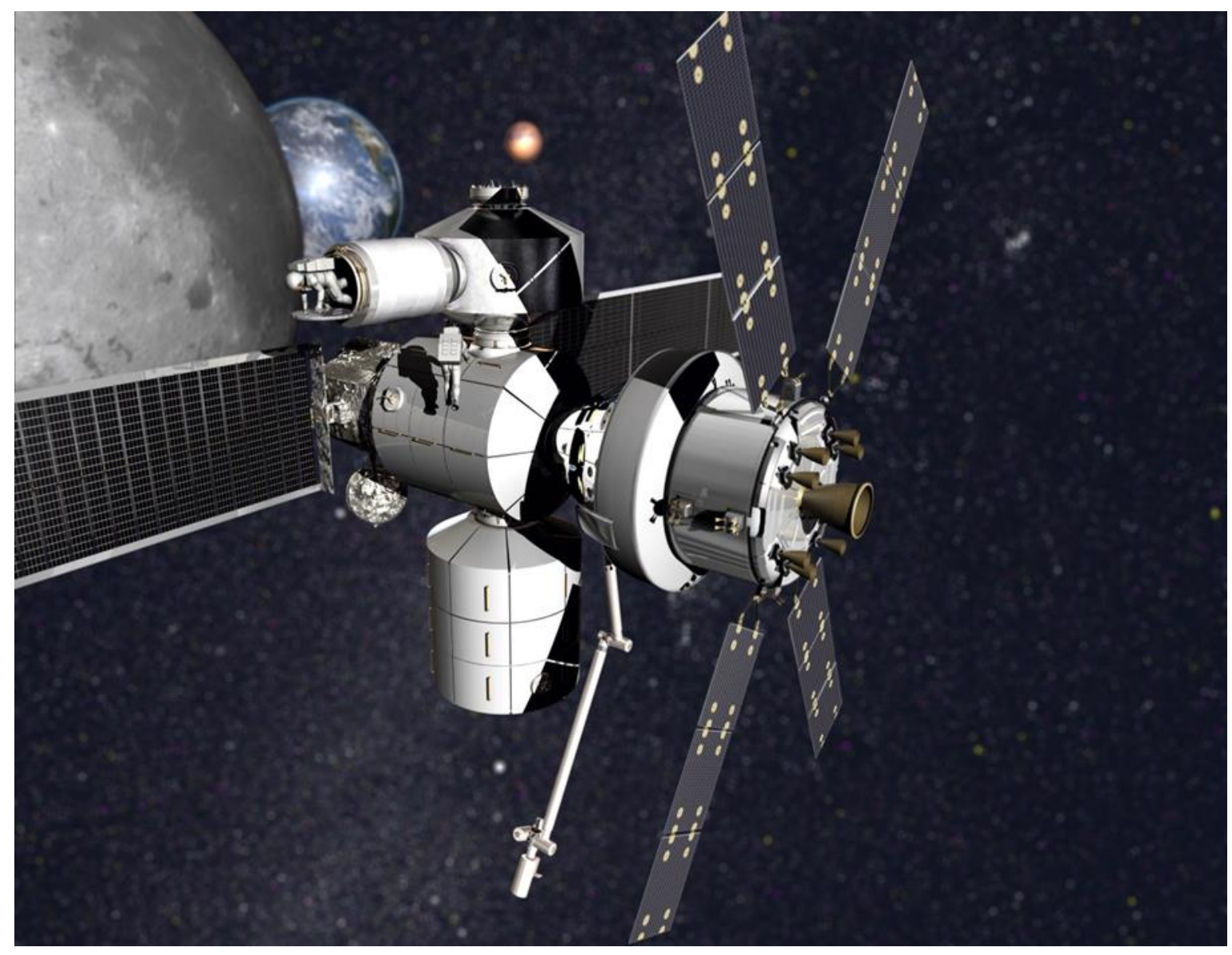

Figure-12- Deep Space Gateway Cislunar Configuration with Orion and Habitation Modules 


\section{Conclusion}

Using results from the MPCV qualifaction and proof of concept testing during the development phase of the program has enabled the MPCV program the ability to accomplish validated acceptance test operations in the O\&C facility without the impact of activating dedicated acoustic and TVAC test chambers at KSC. This approach reduces risk to the MPCV program by avoiding transporting of the spacecraft to other locations for system acceptance testing. Additionally, locating the vehicle acceptance testing operations adjacent to the manufacturing and assembly operations enables rapid spacecraft corrections due to discovery of anomolous test results. These spacecraft testing innovations enable a low risk test approach for the MPCV program and the Deep Space Gateway missions in the future. 